\title{
A failure to find an effect of perceptual set on creativity
}

\author{
MARTIN S. LINDAUER \\ State University of New York, College at Brockport, Brockport, New York
}

\begin{abstract}
The effect of a perceptual set on creativity was tested. Subjects in 16 groups $(N=348)$ were exposed to one of four pretest conditions. One group received practice on the physiognomic perception test, previously shown to be one of the most successful correlates of creativity; another group was exposed to one of the least successful perceptual measures, figure-ground; and in two control conditions, subjects received either a verbal or no pretest. The effects of these pretests were measured by four unusual uses tests of creativity. These measure the number of ideas generated (fluidity) and their unusualness (divergent thinking). None of the pretests, including the perceptual tasks, affected any of the creativity scores. The implications of these null findings, including future directions for research, are discussed.
\end{abstract}

It is not unreasonable to assume that the perceptions of creative people differ from those who are noncreative. "To be creative ... one must literally 'see' the world differently than others do"' (B. O. Bergum \& J. E. Bergum, 1979, p. 61). Creative individuals may take alternate perspectives, do so quickly, and realize their implications more fully; they might also be more flexible, open, and sensitive to perceptual experience (Schachtell, 1959; Tumin, 1954). Consequently, they are capable of looking beyond the obvious when faced with the familiar, or conversely, of seeing more of the familiar in the unusual. In terms of Gestalt psychology, creative people are able to reorganize, restructure, and reconstitute the relevant and irrelevant parts of a problem, and as a result, achieve insight (Wertheimer, 1945). In short, what is seen is related to and influences creative behavior (Getzels \& Csikszentmihalyi, 1975).

The first part of this equation, the relationship between perception and creativity, has been examined in terms of two visual phenomena. In the case of figure-ground perception-in which there are shifts in ambiguous and reversible stimuli (such as the Rubin face-vase and the Necker cube; Lindauer, 1973; Lindauer \& Baust, 1974)the flexibility of creative individuals enables them to see more of the possibilities implied or suggested by an object. Hence, they should be more responsive to figureground fluctuation. However, although some studies find a tie between the number of figure-ground changes and creativity (B. O. Bergum \& J. E. Bergum, 1979; J. E. Bergum \& B. O. Bergum, 1979), others do not (B. O. Bergum \& Falum, 1975; Simpson, Lansky, Lester, \& Paterson, 1983).

Correspondence may be addressed to Martin S. Lindauer, Department of Psychology, Bowling Green State University, Bowling Green, OH 43403-0228.
The other perceptual phenomenon that has been extensively related to creativity is field-independence/dependence (Goodenough, 1976; Jackson, Messick, \& Myers, 1964; Spotts \& Mackler, 1967). Creative individuals could be considered field-independent, in that they are able to extract useful information from a confusing matrix of input without being distracted or overwhelmed by extraneous and irrelevant external cues, as field-dependents would be. Hence, they should do well on measures such as the hidden figures test (HFT; Educational Testing Service, 1962; Jackson et al., 1964), which tests the ease or difficulty of finding a simple figure embedded within a distracting pattern (Witkin et al., 1954). However, the correlational evidence linking creativity to fieldindependence, as it is for figure-ground, is inconsistent. Field-independents have been found to be more creative than field-dependents, but only on some measures (Morris $\&$ B. O. Bergum, 1978); and the two variables were related among women but not men (Bilotta, Guare, \& Lindauer, 1981). And Bloomberg (1971) not only failed to find a relationship between field independence/dependence and creativity, but also between creativity and figureground perception.

More encouraging, though, was Lindauer's (in press) finding of a modest relationship between nearly 60 measures of perception and creativity among 11 different tests. However, neither figure-ground nor field-independence/ dependence measures were very effective. In contrast, other perceptual tests (e.g., physiognomic perception; see Stein, 1975) and the completion of fragmented figures (Street, 1931) were correlated with several creativity tests.

The causal implication of the perception-creativity equation has rarely been pursued (cf. Stein, 1974), perhaps because of these uneven correlational outcomes. The present study, encouraged by the modest success achieved with at least some perceptual tests (Lindauer, in press), was designed to investigate the effect of a perceptual set on the creative response. The set was established by prior 
exposure to two perceptual tests, each of which differed in the robustness of its relationship to creativity (Lindauer, in press). It was predicted that experience with a physiognomy test, which was strongly correlated with several creativity measures, would increase creative responses. Stein (1974, p. 199) has suggested that "to become physiognomic in one's perception" is a means of stimulating hypothesis formulation in creativity. Less effective would be a figure-ground exercise, which was weakly correlated with few creativity tests, and which furthermore has received, at best, mixed results in other studies (e.g., B. O. Bergum \& J. E. Bergum, 1979; B. O. Bergum \& Falum, 1975; J. E. Bergum \& B. O. Bergum, 1979; Simpson et al., 1983). Both perceptual tasks, though, should lead to more creative responses than either the absence or the minimal presence of a perceptual set. The latter were represented by two conditions. In one, there was no pretest experience (control-blank); and in the other, an irrelevant digit-substitution task was used (control-filler).

The effect of these two perceptual and nonperceptual sets on creativity was measured by four "uses" tests (Guilford, 1975). The tests require subjects to imagine the uses of four ordinary objects (a paper clip, brick, and four or two circles). The total number of uses listed is a measure of subjects' "fluidity", and their unusualness taps "originality", (or divergent thinking). These tests, like the physiognomic pretest, require flexibility, openness, and the taking of a nonliteral, imaginative, and going-beyond-the-given attitude. Two of the dependent measures, furthermore, which display two and four circles, are visual tests. Hence, they are congruent with the perceptual pretests. The tests also avoid a criticism leveled at many other creativity tests (e.g., the Remote Associates Test; S. A. Mednick, 1962; S. A. Mednick \& R. S. Mednick, 1967), in that more than one possible answer can be correct. This criterion allows for divergent thinking, which unlike convergent thinking, where only one answer can be correct, is characteristic of the openendedness of creativity.

It was predicted that prior exposure to the physiognomic perception task should increase the number and unusualness of the responses to the four measures of creativity. Exposure to the figure-ground pretest, or to the two nonperceptual control conditions, however, would have less or no effect.

\section{METHOD}

\section{Subjects}

There were 348 subjects, nearly all of whom were undergraduate volunteers who participated for credit from introductory psychology courses; the exceptions were 30 students from an advanced class in psychology. The majority of subjects were tested in small groups of 2-5 each; about one-third were tested in their classes. There were more women $(67 \%)$ than men in the study ( 234 and 114 , respectively), which is representative of the student profile in psychology courses.

\section{The Pretests}

The physiognomic pretest (Stein, 1975) was given to 87 subjects (35 men, 52 women). The test presents a series of meaningless stimuli, which subjects describe on a scale that indicates either their imaginative (i.e., physiognomic) or literal connotations-jagged lines, for example, are "angry" or jagged. The former (physiognomic) reaction reflects a nonrigid and flexible "going beyond the given," a quality creative persons are likely to show.

The figure-ground stimuli were shown to 88 subjects (19 men, 69 women). Thirteen ambiguous figures were taken from various sources (Lindauer, 1973; Lindauer \& Baust, 1974). They included, for example, the wife/mother-in-law figure, a pirate/rabbit, a dove/hawk; the Rubin face-vase was used as a sample training stimulus. Each ambiguous stimulus had at least two possible meaningful figures embedded within it; the total number of figures that could be seen was 29 . The stimuli, on individual pages, were shuffled and placed in a booklet. Subjects circled and labeled what they saw. A recognition measure was used, rather than rate of reversals, since the former lends itself to group testing. Thus, the task measured whether there was reversal or not. Reversible stimuli (e.g., the Necker cube), which have no easily identifiable meaningful shapes, were not used.

Subjects taking the physiognomic and figure-ground tests were also divided into high and low scorers on the basis of their median scores ( $=96.00$ and 24.50 , respectively); the former test, for which norms are available (Stein, 1975), is about the average mean score for undergraduate nonartists with nontechnical majors. The physiognomic and figure-ground tasks (fully described in Lindauer, in press) were presented for $10 \mathrm{~min}$. Most subjects completed the tests within the allotted time, although figure-ground identification tended to take a little longer.

In the two control conditions, 81 subjects in the control-blank condition had no pretest ( 25 men, 56 women); and 92 subjects in the control-filler task received a nonperceptual digit substitution task (35 men, 57 women). Subjects in the control-blank condition were given a 10min lecture on perception. It included information on and demonstrations of physiognomy and figure-ground, and a brief introduction to their possible role as a "warm-up" in doing imaginative types of tasks. Similar information, but in less detail and for $5 \mathrm{~min}$ only, was presented in the control-filler condition. It was followed by a 5-min warm-up digitsubstitution task. The two experimental conditions received a similar but even briefer "lecture." Thus, all of the subjects knew they were participating in a study on the role of perceptual set on imagination, in which physiognomy and figure-ground were demonstrated, but to varying degrees. Thus, except for exposure to a pretest, or none, the conditions were equivalent.

\section{The Posttests}

The pretests (if used) were immediately followed by one of the four creativity tasks, for which $3 \mathrm{~min}$ were allowed. The creativity test, randomly chosen from the four available, was located in the same booklet as the pretests (except for the control-blank group, which had no pretest). The four- and two-circle tasks were pictured at the top of the response sheet: Two or four circles were shown lying on an open-rectangle line drawing. The subjects were told to "imagine all the things this could be." For the paper-clip and brick tasks, the response sheet was headed by instructions to "list all the uses you can think of for a paper clip [or brick]."

An unusual (divergent-thinking) measure was obtained for the paperclip and brick tests only, because these could be scored relatively more easily than the other two measures. A divergent use for a paper clip was one in which the response was unrelated to holding or fastening; and a divergent use for a brick was unrelated to construction. The experimenter judged unusualness. A random sample of unidentified responses was judged 2 weeks after the initial categorizing of unusual responses; very few changes (less than $1 \%$ of the cases) were found.

The subjects were assigned to either the experimental or the control tasks in the order in which they appeared at the laboratory, and they were tested in small groups. The subjects in the experimental sessions received one of the two perceptual tasks; those in the control sessions received only one of the two control tasks (since they differed in administration).

\section{RESULTS}

\section{Equivalence between the Two Pretest Perception Conditions}

The groups receiving the two perceptual pretests did not differ from one another prior to receiving the creativity 
tests. (There was no basis for comparing the pretest scores of the control groups, since the control-blank condition received no pretest, and the control-filler condition received an irrelevant task.) The four groups initially exposed to a figure-ground task (it preceded each of the four creativity measures) did not differ from one another $[F(3,72)<1]$. High and low scorers did differ, as expected, from one another $[F(1,72)=59.93, p<.01]$. The figure-ground scores did not differ as a function of sex $[F(1,72)<1]$; and the latter did not interact with the high-low measure $[F(1,3)<1]$. The four groups receiving the physiognomic pretest also did not differ from one another $[F(3,69)=1.78, p>.05]$. And, as in the figure-ground conditions, the high and low scorers differed $[F(1,73)=45.87, p<.01]$, and there was neither a sex difference $[F(1,73)<1]$ nor an interaction $[F(1,3)<1]$.

\section{Differences between the Creativity Measures}

None of the creativity scores that followed the four experimental and control conditions differed from one another, whether comparisons were based on the total number of uses or their unusualness $[F(3 / 72-92)<1.13$, $p>.05 ; d f \mathrm{~s}$ vary because of differing $n \mathrm{~s}]$. For example, the mean numbers of uses for a paper clip were 7.95 and 7.71 when the task was preceded by the figure-ground and physiognomic tasks, respectively; and when preceded by the control-blank and control-filler conditions, the means were 6.62 and 7.61 , respectively $[F(3,80)=1.13$, $p>$.05].

Furthermore, no differences emerged when the creativity scores were examined in terms of the subjects who scored high or low on the figure-ground and physiognomic tests $[F(1 / 30-41)<1]$. Similarly, when the two perceptual and two control groups were combined (justified because of the absence of any difference between the separate sets of scores), the creativity scores again did not differ $[t=0.78-1.48, p>.05, d f=78-92]$. Male and female differences played no role in general $[F(1 / 72-92)<1]$ or in interaction with any other factor $[F(3 / 72-90)<1.30, p>.05]$.

\section{Correlations between the Perception and Creativity Tasks}

These nondistinguished findings were paralleled by a correlational analysis of the data. There were no significant correlations between the two perception tasks and the four creativity measures. (This outcome parallels the pattern of other correlational studies; see Lindauer, in press.) Closest to significance were the physiognomic and fourcircle scores $(r=.46, t=1.92)$, followed by the relationship between figure-ground and the total paperclip scores $(r=.31, t=1.45)$. The total and divergent scores on the paper-clip and brick tests, happily, were correlated with one another $(r=.86$ and .64 , respectively, $t \geq 3.39$ ).

\section{DISCUSSION}

In short, very little happened. Exposure to two perceptual tasks, physiognomy and figure-ground, did not differentiate the fluidity and divergency of the responses to four creativity tasks (the number of uses generated by a paper clip, brick, and four or two circles). Furthermore, no effect was found with finer analyses of the data: The creativity responses of the high and low scorers on the two perception tasks were not distinguished; the homogeneity of the responses persisted when the two perceptual and nonperceptual pretests were combined; and the sexes did not differ. Finally, none of the perception and creativity measures were correlated with one another.

There are several ways of accounting for the failure to find an effect (which is why "null" results are usually not reported). It could mean that perception (or a perceptual set) has no effect on creativity. Or, there is an effect, but tasks that establish stronger and more direct orientations and predispositions than those used in this study are needed (e.g., instructions to "brainstorm"; Stein, 1974). A less ambiguous explanation is that the orientation received by subjects prior to the study made the specific perceptual manipulations superfluous. In stating the purpose of the study ("the role of set on imagination"), and in giving examples of physiognomy and figure-ground to all the subjects (so as to ensure the equivalence between experimental and control conditions), too much information was revealed. Consequently, all subjects may have gained a perceptual set, and it was sufficient to affect the creativity scores equally.

Another likely possibility is that $10 \mathrm{~min}$ of exposure to a perceptual task was too brief for an effect to occur. A more long-standing and pervasive perceptual trait, such as cognitive style (Goodenough, 1976; Witkin et al., 1954), would have been more effective than a set developed within a brief experimental context. This may be why at least some correlational studies, relying on personal characteristics rather than transient experimental manipulations, have been more successful (Lindauer, in press). Thus, an individual-difference approach to the perceptioncreativity connection may be more relevant than an experimental strategy. Perception as a personality trait is more powerful than perception as a temporary set. Accordingly, the preselection of subjects with extremely high and low scores on the perceptual tests might be more useful in differentiating the creativity responses. The differences between the perceptual scores of those who participated in this study were not great (e.g., the median figure-ground score was close to the maximum).

Null findings are ordinarily not reported because they are difficult to interpret. However, the present results are credible because of the large $N$, the use of several perceptual and nonperceptual test conditions, and the reliance on four measures of creativity. This effort, although disappointing, at least suggests several procedures that might be more successful. Two possibilities that deserve further exploration would be to give subjects more time on the perceptual pretests, and to select subjects who score at the extremes on these tests. The abundance of speculation about the relationship between perception and creativity (e.g., Ghiselin, 1955; Osborn, 1953; Schachtell, 1958; Tumin, 1954; Wallas, 1926), thus far supported by modest correlational findings (Lindauer, in press), encourages further efforts.

\section{REFERENCES}

Bergum, B. O., \& Bergum, J. E. (1979). Creativity, perceptual stability, and self-perception. Bulletin of the Psychonomic Society, 14, 61-63.

Bergum, J. E., \& Bergum, B. O. (1979). Self-perceived creativity and ambiguous figure reversal rate. Bulletin of the Psychonomic Society, 14, 373-374.

Bergum, B. O., \& Falum, L. E. (1975). Perceptual stability, image size, binocularity and creativity. Perceptual \& Motor Skills, 41, 667-671.

BilotTa, J., Guare, J., \& Lindauer, M. S. (1981). The relationship between field-independence/dependence, creativity, and physiognomy among men and women. JSAS: Catalog of Selected Documents in Psychology, 11 (No. 2287). 
BLoOmberg, M. (1971). Creativity as related to field independence and mobility. Journal of Genetic Psychology, 118, 3-12.

Educational Testing Service. (1962). Hidden figures test-V. Atlanta, GA: Author.

Getzels, J. P., \& Csikszentmihaly, M. (1975). From problem solving to problem finding. In I. A. Taylor \& J. W. Getzels (Eds.), Perspectives in creativity (pp. 90-116). Chicago: Aldine.

GHISELIN, B. (ED.). (1955). The creative process. New York: Mentor. Goodenough, D. R. (1976). The role of individual differences in field dependence as a factor in learning and memory. Psychological Bulletin, 83, 675-694.

GUILFORD, J. P. (1975). Creativity: A quarter century of progress. In I. A. Taylor \& J. W. Getzels (Eds.), Perspectives in creativity (pp. 3759). Chicago: Aldine.

Jackson, D. N., Messick, R., \& Myers, C. T. (1964). Evaluations of group and individual forms of embedded-figures measures of fieldindependence. Educational \& Psychological Measurement, 177, 192.

Lindauer, M. S. (1973). The extent of illusory effects for 32 illusions. Perceptual \& Motor Skills, 36, 887-894.

LINDAUER, M. S. (in press). The relationship between tests of creativity and perception. ERIC Document Reproduction Service.

Lindauer, M. S., \& Baust, R. F. (1974). Comparisons between 25 reversible and ambiguous figures on measures of latency, duration, and fluctuation. Behavior Research Methods \& Instrumentation, 6, 1-9.

MEDNick, S. A. (1962). The associative basis of the creative process. Psychological Review, 69, 220-232.

Mednick, S. A., \& Mednick, R. S. (1967). Remote associates test. Boston: Houghton Mifflin.
MoRrIs, T. L., \& BERGUM, B. O. (1978). A note on the relationship between field-independence and creativity. Perceptual \& Motor Skills, 46, 1114.

OsBorn, A. F. (1953). Applied imagination. New York: Scribner. SCHACHTEll, S. (1959). Metamorphosis. New York: Basic Books. Simpson, M. T., Lansky, L. M., Lester, R. J., \& Paterson, J. M. (1983). Figure reversals and creativity: A research note. Perceptual \& Motor Skills, 57, 582.

SPOTTS, J. V., \& MACKLER, B. (1967). Relationship of field-dependent and field-independent cognitive styles to creative test performance. Perceptual \& Motor Skills, 24 (Monograph Supplement 2-V24), 239-268.

SteIN, M. I. (1974). Stimulating creativity (Vols. 1-2). New York: Academic Press.

Stein, M. I. (1975). The physiognomic cue test: Manual. New York: Behavioral Publications.

STREET, R. F. (1931). A gestalt completion test. New York: Teachers College Press, Columbia University.

Tumin, M. (1954). Obstacles to creativity. ETC, 11, 261-271.

Wallas, R. (1926). The art of thought. New York: Harcourt Brace. Wertheimer, M. (1945). Productive thinking. New York: Harper.

Witkin, H. A., Lewis, H. B., Hertzman, M., Machover, K., MeissNER, P., \& WAPNER, S. (1954). Personality through perception. New York: Harper. 